
\title{
UC scientists help growers cope The Energy Crunch with energy crunch
}

T he bad news is that today's energy crunch could hit agricultural operations hard. Although energy accounts for less than $5 \%$ to $10 \%$ of total costs for many operations, increased power rates can still have a major impact because profit margins are so low in agriculture. And blackouts could have dire consequences: without power, strawberries can decay rapidly, cows can't be milked, and chickens can die within 20 minutes.

The good news is that the current energy problem is likely to be short-term, with the greatest impacts this summer and next summer. "After that we should be in much better shape,"

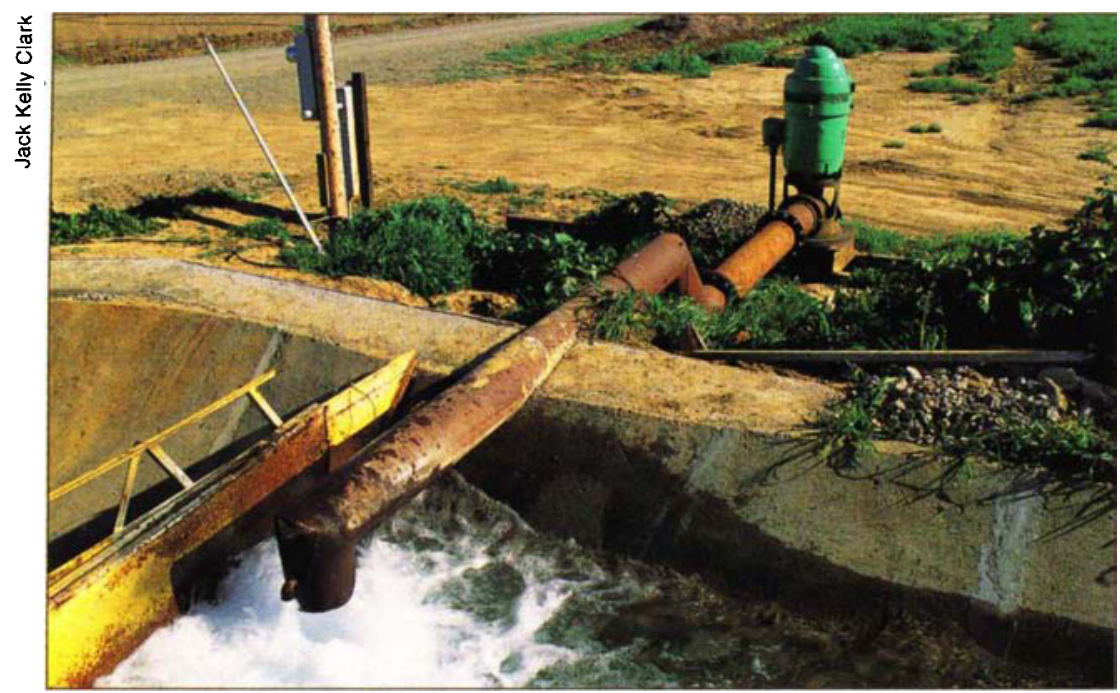

Irrigation can be one of the highest electricity costs for growers, particularly those pumping water from wells. According to UC experts, growers can cut energy costs by improving the efficiency of pumps, switching to more efficient irrigation systems or transition from electric to diesel engines.
UC Davis biological and agricultural engineer Jim Thompson says.

California's current energy crunch can be attributed to a confluence of factors; the primarily culprit is market destabilization linked to power deregulation, followed by minimal increases in the state's generating capacity in recent years.

On peak-use summer days, the state's electricity reserve dropped from $6 \%$ in 1997 to a mere $2 \%$ in 2000. Since then, the state has increased its generating capacity by adding several new power plants. In early 2001, Governor Davis signed a series of executive orders expediting the review and permitting process for new power-generating facilities in California while maintaining environmental standards. An additional 20,000 megawatts is expected to go online by July 2004, starting with 5,000 additional megawatts by July 2001 and 5,000 more megawatts by July 2002 .
However, prices are still increasing in most parts of California, and Thompson cautions that high electricity costs could have a long-term impact on large agricultural users such as feedmills, and poultry and dairy operations.

In contrast, natural gas is plentiful but its availability has been hampered by inadequate transportation and storage, Thompson says. Utilities are adding pipelines and underground storage capacity, and natural gas and petroleum prices are beginning to drop. Natural gas is currently most heavily used by greenhouses and food processors and driers.

Conservation. In the aftermath of the last energy crisis in the 1970s, technology for conserving energy improved dramatically, Thompson says. Conserving power usually means investing in new equipment, such as highefficiency cooling fans for poultry buildings, or more efficient refrigeration systems for perishable products.

Some agricultural operations may not need to conserve energy yet but should prepare nonetheless. For example, beef production uses a relatively small amount of energy, primarily for growing and processing feedlot grain. Moreover, beef producers can absorb today's high electricity prices because beef prices are also at a high. But beef prices are cyclical and could be at a low in 5 years, which means it's worth learning to conserve energy now, UC Davis livestock specialist James Oltjen says.

Unfortunately, conserving more energy is not an option for all agricultural operations. For example, prune dehydrators are already operating their equipment at high efficiency so it's not worth investing in new equipment because they only operate about 20 days per year. "They're in a tough spot," Thompson says.

Optimizing irrigation energy use. Irrigation can be one of the greatest electricity costs for growers, particularly those pumping water from deep wells in the western San Joaquin Valley. According to UC experts, there are three main ways of cutting irrigation energy costs.

The first way is to improve the efficiency of water pumps, repairing or replacing them as necessary. "It's not uncommon for old wells to have pumps that are operating at $50 \%$ to $60 \%$ efficiency," UC Cooperative Extension irrigation specialist Blake Sanden of Bakersfield says. Be- 
cause a more efficient pump means greater water flow, the next step would be to decrease irrigation times. Otherwise growers end up using more water - and so more electricity - than necessary.

The combination of increased pump and irrigation efficiency can reduce energy costs considerably. For example, in a 150 -acre almond orchard with an optimal sprinkler irrigation schedule, improving pump efficiency from $55 \%$ to $70 \%$ and irrigation distribution uniformity from $70 \%$ to $90 \%$ could save about $\$ 16,000$ in electricity annually.

The second way that growers can cut irrigation energy costs is to switch to more efficient irrigation systems, such as from furrows to sprinklers or drip. But UC Davis irrigation specialist Blaine Hanson cautions that these highefficiency irrigation systems could actually use more energy because they use electricity to maintain their water pressure.

"It depends on the crop and soil. It's not universally true that high-efficiency irrigation systems save energy. It's site-specific," Hanson says. For processing tomatoes grown in the salty, clay soil of the San Joaquin Valley, switching from sprinklers to drip can increase the yield so much that it more than pays for the conversion costs. But that may not be true for row corn and other lower cash-value crops.

The third method is to switch from electric motors to diesel engines, Hanson says.

Because electricity rates have skyrocketed in San Diego and Ventura counties, many growers have converted to diesel. The decision is not as straightforward in areas where electricity rates have increased less drastically.

While diesel engines are about one-third cheaper to run than electric motors, they can cost several times more. "Growers are caught in a bind - they can make short-term decisions but not long-term ones," Hanson says. "Diesel is economical now but will it be in 2 years?"

Another factor in deciding whether to switch to diesel is air quality. While agriculture is currently exempt from some air pollution regulations, Hanson says this may change. Growers who switch to diesel should purchase appropriate pollution control devices, he advises.

Shift to nonpeak usage times. Electricity rates are highest between noon and 6:00 p.m., when temperatures and the demand for electricity rise. Some growers are reducing energy costs by shifting their hours of operation to nonpeak times. For example, bag salad packinghouses used to start at 8:00 a.m. and work all

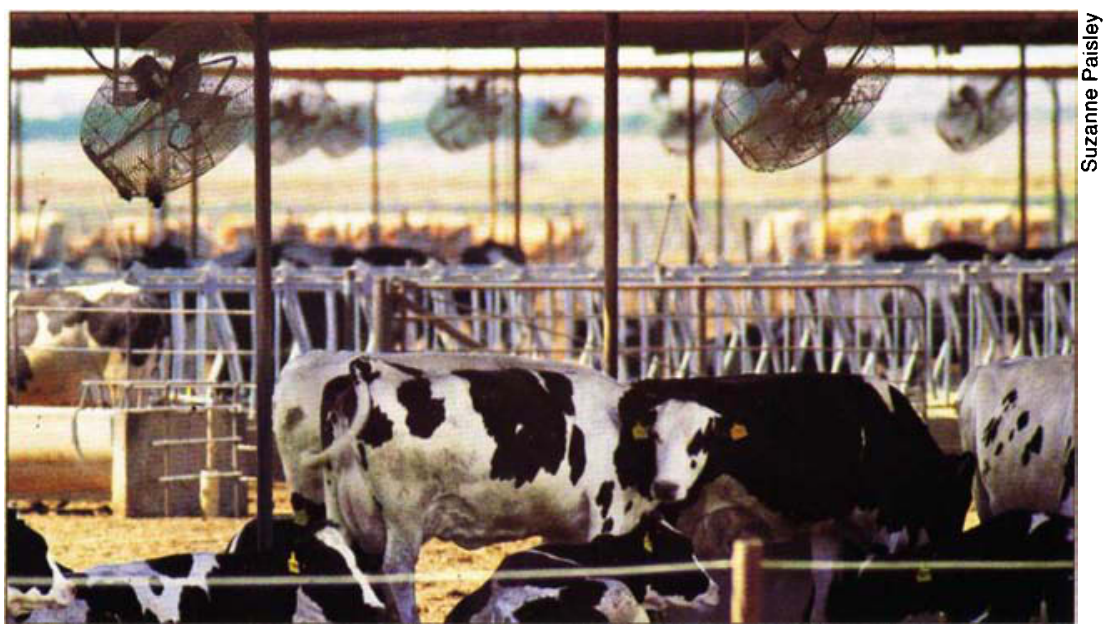

day; now many are starting at 6:00 p.m. instead, Thompson says.

However, switching to nonpeak times is not an option for many agricultural operations, Thompson says. Many perishables require cooling soon after harvest. For example, without refrigeration strawberries start to decay in about 2 hours, and sweet corn loses sugar in about 4 hours. In addition, many dairy operations run around the clock and cows can't wait to be milked. On the other hand, hens can't be hurried to lay eggs and they usually don't finish until about 11:00 a.m., which means the eggs must be processed during peak times.

Backup generators. Growers who depend on continuous power should have backup generators to protect them from blackouts, which are most likely to occur for an hour or two between the peak times of noon and 6:00 p.m. "Power is vital to animals in environmentally controlled buildings," UC Davis poultry specialist Ralph Ernst says. "They're extremely vulnerable to power outages."

About $60 \%$ to $70 \%$ of California's egg and broiler production takes place in completely enclosed, insulated and fan-cooled buildings. No power means no airflow, which soon becomes lethal. Chickens start dying when the temperature reaches $110^{\circ} \mathrm{F}$, which could happen within 20 minutes of losing airflow, Ernst says. Ironically, most of this temperature increase comes from the birds' bodies themselves: broilers in enclosed buildings generate about $90 \%$ of the interior heat.

Backup generators are expensive - about $\$ 50,000$ for systems that can generate the 250 kilowatts that large poultry operations require - but losing the 20,000-plus birds per building would be far more expensive, Ernst points out. - Robin Meadows
Dairies are among the agricultural industries most vulnerable to power outages and rolling blackouts. While growers and livestock producers are advised to switch energy usage to nonpeak times when prices are lower, many operations do not have that option; for example, cows must be milked on schedule and eggs must be processed soon after they are laid. 